\title{
Editorial
}

\section{La salud de la pobreza y la pobreza de la salud}

La epidemia de dengue hemorrágico que ha hecho estragos en la población infantil salvadoreña pudo haber sido evitada si el Ministerio de Salud Pública hubiera atendido las advertencias de los especialistas y no hubiera descuidado las condiciones generales de salubridad del país. Organismos internacionales y especialistas advirtieron al gobierno salvadoreño que, dado el aparecimiento progresivo de diferentes tipos de virus del dengue y la alta densidad poblacional del mosquito transmisor, era previsible el aparecimiento del dengue hemorrágico, de la misma manera que ahora estarían dadas las condiciones para el aparecimiento de la fiebre amarilla, puesto que el vector es el mismo y está fuera de control. En parte, esto es así por las características del virus y del hospedero; pero, en parte, es resultado también del medio ambiente natural y social, que, dejado a sí mismo, facilitó la expansión del vector que lo transmite.

Ante los primeros brotes de la enfermedad, el Ministerio de Salud Pública reaccionó ocultando su existencia, alegando que no eran casos confirmados. El año pasado hubo un caso que debió alertar a las autoridades de salud, pero éstas lo consideraron aislado y lo dejaron pasar, esperando que lo peor no sucediera. Cuando a comienzos de este año aparecieron más brotes, las autoridades calcularon que eran casos aislados, que no desembocarían en una epidemia. El año pasado ya habían corrido el albur y habían salido bien libradas; este año adoptaron la misma actitud, pero el resultado es la creciente lista de niños hospitalizados con dengue hemorrágico. La reacción gubernamental ha llegado demasiado tarde como para impedir la muerte de más de treinta niños, aunque la acción urgente era indispensable para contener la propagación del virus y mantener con vida a los infectados.

La emergencia nacional decretada por el gobierno es una medida desesperada que busca llamar la atención sobre la crisis y provocar la colaboración 
de la población y la ayuda de la comunidad internacional. Todo ello es necesario, dado el desarrollo de la epidemia. Sin embargo, una vez ésta haya sido controlada, habría que dar un paso más ambicioso y comenzar la reforma del sistema de salud. La epidemia de dengue hemorrágico es una manifestación clara del alarmante deterioro de dicho sistema y de las consecuencias fatales que tiene para la población más vulnerable. En realidad, es todo el sistema el que debiera ser puesto en emergencia nacional. Es cierto que se han elaborado planes de salud, de atención primaria comprensiva y selectiva e incluso una política "de salud para todos" en el 2000, pero en la práctica ninguno de ellos ha demostrado ser el instrumento idóneo para garantizar la salud del pueblo salvadoreño. La atención primaria comprensiva, por haber sido desnaturalizada, y los otros planes, por insuficientes. Es entonces cuando el gobierno y el sector privado piensan en la privatización como la solución definitiva, pero en esto se equivocan.

La epidemia de dengue hemorrágico cuestiona la eficacia de todos esos planes, puesto que es una enfermedad de la pobreza, relacionada con la elevada densidad de la población, la urbanización no planificada, la concentración de población en asentamientos sin agua potable, sin alcantarillado y rodeados de basura. La salud y, o las enfermedades del pueblo salvadoreño están relacionadas directamente con su pobreza y de ella se deriva la pobreza de su salud.

\section{El estado de la salud de la pobreza}

Los dos sectores más vulnerables son los niños y la mujer. Las enfermedades perinatales ocupan el primer lugar como causa de muerte en los menores de un año, mientras que las enfermedades infecciosas, las intestinales y las neumonías ocupan el segundo lugar. La explicación de las primeras estriba en la poca salud pública existente y en la falta de atención médica prenatal, en el parto y después del nacimiento; mientras que la de las segundas, en la ausencia de infraestructura básica —agua potable, disposición adecuada de aguas servidas y electricidad - y por contaminación del medio ambiente, la desnutrición y el estrés. El espacio reducido y el hacinamiento en los hogares rurales y de las zonas marginadas, por lo general, ponen en peligro la salud de sus habitantes, sobre todo cuando la cocina se encuentra en el interior y el combustible utilizado es muy contaminante - como es el caso de la leña. Es así como, aunque la mortalidad antes de cumplir el primer año de vida ha experimentado un descenso significativo —al pasar de 41 a 35 muertes por mil, en el quinquenio 1988-1993, según informes de Naciones Unidas-, sigue siendo alta para el promedio mundial. La misma tendencia se observa en la mortalidad $\in$ n la niñez -entre el primer año de vida y los cinco años. Las diferencias entre la zona urbana y la rural son chocantes, mientras que en la primera mueren 33 infantes y niños por cada mil, en la segunda mueren 50. 


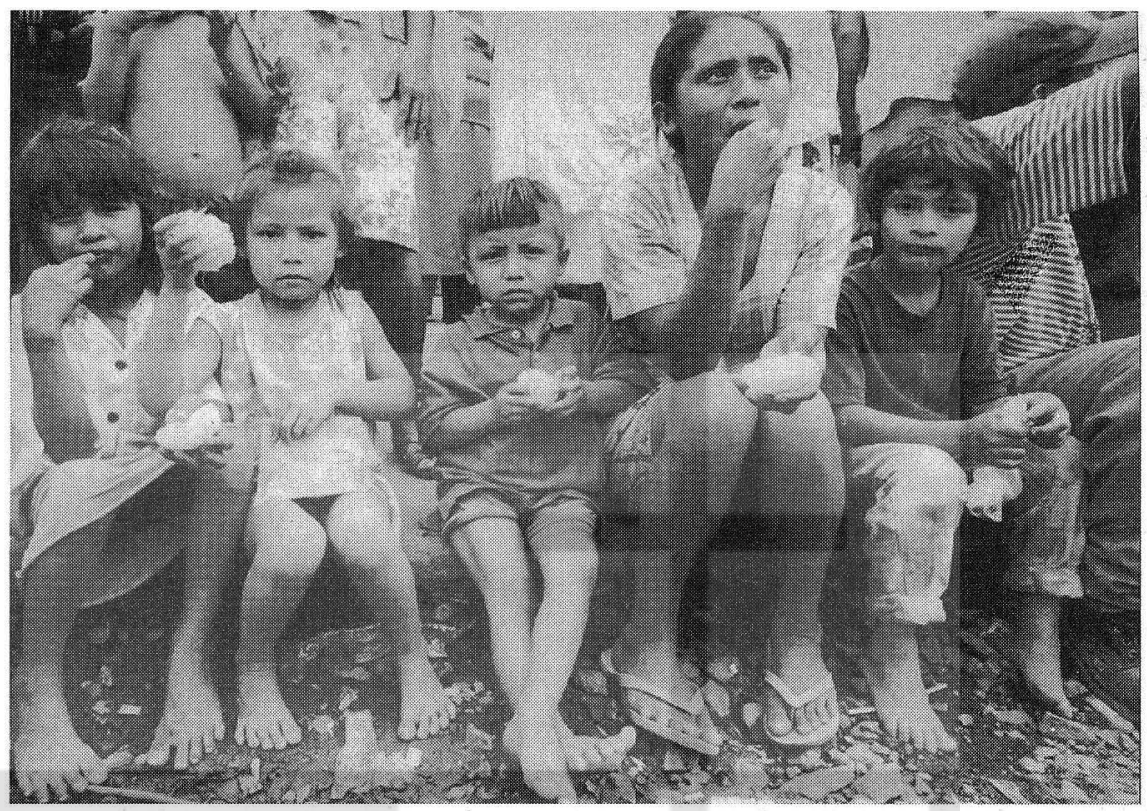

El estado de la desnutrición, un elemento clave de la salud pública, es similar. Aunque en el mismo quinquenio (1988-1993), la alimentación de los niños mayores de tres meses y menores de cinco años experimentó una leve mejora, la siruación sigue siendo muy grave, puesto que uno de cada cinco niños menores de cinco años sufre desnutrición severa, lo cual afecta su crecimiento y el desarrollo de sus facultades. La desnutrición crónica es peor en el área rural que en la urbana, donde es más del doble. El retraso en el crecimiento de los niños por desnutrición crónica no sólo afecta su rendimiento escolar, sino que también, más tarde, determina sus posibilidades para encontrar un empleo bien remunerado $y$, por lo tanto, tendrá menos oportunidades para romper el círculo de la pobreza. La desnutrición general y crónica es una de las causas de la deserción en el primer grado de educación básica y de la repitencia..

Una de las causas principales de muerte en la mujer, en edad fértil, es el embarazo. Cerca del 80 por ciento de las muertes de mujeres, ocurridas en los años recientes, es atribuible a este último — según datos de Naciones Unidas. El 60 por ciento de las fallecidas no estaba bajo control perinatal y casi el 17 por ciento tenía entre quince y diecinueve años. Aunque la mortalidad materna disminuye cuando hay control perinatal y cuando el parto es atendido institucionalmente, en 1997, menos de la mitad de las mujeres embarazadas y de los partos recibían esa clase de atención. Sin embargo, la mortalidad materna muestra una tendencia a la disminución al pasar de 158 a 120 mujeres fallecidas por cien mil nacidos vivos. El tumor maligno en el útero, una formación infecciosa, transmitida sexualmente en casi todos los 
casos y, por consiguiente, evitable, causó el 25.7 por ciento de las muertes debidas a tumores en 1998 (405 muertes). No obstante que este tipo de cáncer afecta a la mujer salvadoreña mucho antes que el sida, las autoridades de salud poco se han preocupado por prevenirlo.

Según el Ministerio de Salud Pública, en 1999, el 86 por ciento de las enfermedades eran infecciosas. Sin embargo, el informe de la Organización Panamericana de la Salud - Organismo Mundial de la Salud, para el mismo año, distribuye las muertes de la manera siguiente: 22.1 por ciento por lesiones intencionadas o no y accidentes, 16.8 por ciento por enfermedades transmisibles, 16.8 por ciento por enfermedades del sistema circulatorio, 11 por ciento por tumores y 30.2 por ciento por otras causas no infecciosas.

La mayor demanda de servicios de salud se presenta en unidades o centros de atención comunitaria - puestos, unidades y centros de salud y dispensarios. Sin embargo, el presupuesto asignado a estos servicios es menos de la mitad del asignado a los hospitales, aun cuando es de sobra sabido que una buena atención comunitaria y primaria disminuiría de manera considerable los gastos de hospitalización. Eso sin considerar que tres cuartas partes del presupuesto están destinadas a salarios y poco más del 10 por ciento a medicamentos - los cuales son escasos y caros. El sistema nacional presta dos clases de servicios: quienes pueden pagar reciben más y mejor atención en el seguro social, pero quienes no pueden hacerlo reciben atención casi gratuita en menor cantidad y de menor calidad en los hospitales y centros nacionales. Ahora bien, la calidad de la atención prestada por los centros de atención comunitaria y los hospitales del sistema público de salud varía de un departamento a orro. No es extrańo, entonces, que la mayor parte de la población reclame más puestos de atención comunitaria, dotar a estos centros y a los hospitales con medicamentos y material, así como también controlar el precio de los mismos.

Al analizar el estado del sistema de salud del país se constata que la apreciación de la población es correcta: no existen los recursos humanos -investigadores, enfermeras, administradores, contables, etc. - adecuados para resolver los problemas más comunes, tal como lo ha puesto en evidencia la epidemia de dengue hemorrágico,...

No toda la población reacciona de la misma manera ante una enfermedad, sino que aquélla depende directamente del ingreso familiar. El 20 por ciento más pobre es más propenso a no buscar atención, sobre todo en la zona rural; mientras que, en la zona urbana, tiende a automedicarse, lo cual, si no se poseen los conocimientos básicos para interpretar los síntomas e 
identificar el medicamento adecuado, puede llevar a complicaciones y a gastar bastante más de lo previsto. La medicina natural también tiene sus riesgos por falta de educación. La distancia a la cual se encuentra el centro de salud de la comunidad —en particular en la zona rural_, la baja calidad de su servicio, la desconfianza y la llamada cuota social que se cobra al usuario no lo hace atractivo para los más pobres, quienes dependen así sólo de sus conocimientos básicos de salud —de las enfermedades y del uso de los medicamentos. En el otro extremo del ingreso familiar urbano y rural prevalece la medicina privada, aunque más en el primer sector que en el segundo. El seguro social presta servicios a los estratos de ingresos más altos y a los sectores formal y urbano. Esto significa que los más ricos y los más pobres son los que menos utilizan el sistema nacional de salud. Por lo tanto, quienes más lo utilizan son los estratos intermedios entre los dos extremos del ingreso familiar. A medida que aumenta el ingreso familiar, la distancia deja de ser un problema, pero no así la calidad y la confianza.

Más de la mitad de la población que se enferma busca curación fuera de los sistemas establecidos. Sólo el 20 por ciento que se enferma y busca atención, acude al sistema nacional de salud. La mayoría es atendida en las unidades, los centros y los puestos de salud. Los más pobres son los que menos utilizan este sistema; casi la mitad de quienes lo usan cuenta con un ingreso familiar igual o inferior al salario mínimo. Cerca de la mitad de la población enferma se automedica. Es así como los más pobres, que son los que más se enferman, son los que menos atención institucional reciben y los que más se automedican. Correspondientemente, el gasto en salud tiende a ser mayor cuanto más alto es el ingreso familiar; pero los pobres pagan un porcentaje más elevado que aquellos que se encuentran en los estratos superiores del ingreso. Por eso, los pobres, quienes son los que más se enferman, son los que menos reaccionan ante esta situación, la cual, además, tiende a volverse más crítica y, por consiguiente, a demandar más recursos para superarla.

No obstante las evidentes y clamorosas deficiencias del sistema de salud pública, estas no se encuentran entre los problemas del país más citados por la opinión pública. Las quejas se concentran en los hospitales, pese a que la mayor parte de la gente que acude al sistema es atendida en los centros, las unidades y, o los puestos de salud. Esto se explica porque las expectativas de los enfermos en este nivel de atención son pocas. Para ellos, es un lugar de paso, en el cual deben ser evaluados y remitidos al hospital, donde esperan recibir la verdadera atención. Pero al llegar a éste deben aguardar turno, a veces horas interminables, llenar formularios que por lo general no comprenden, pagar la llamada cuota social y además proporcionar sangre y medicamentos e incluso instrumental que el hospital con frecuencia no posee. Los usuarios del sistema lo que más resienten es el elevado costo de los servicios, mientras que la calidad pasa a un segundo plano, lo cual se explica porque la población no acude al sistema por esta última razón. Cuando no se puede pagar, cuando no hay medicamentos ni equipo y cuando el servicio es defi- 
ciente, la calidad es muy relativa, aunque cada vez hay más quejas por la falta de preparación de los médicos. En cambio, la población cuyo ingreso familiar es superior al promedio nacional no considera que el costo de los medicamentos sea un obstáculo.

Al analizar el estado del sistema de salud del país se constata que la apreciación de la población es correcta: no existen los recursos humanos -investigadores, enfermeras, administradores, contables, etc.- adecuados para resolver los problemas más comunes, tal como lo ha puesto en evidencia la epidemia de dengue hemorrágico, el énfasis está puesto en prácticas de diagnóstico y de curación caras y a veces también innecesarias, escasea el material de laboratorio, el personal de servicio es incapaz de comunicarse con el enfermo y sus familiares, éstos utilizan proveedores diversos y demandan medicamentos innecesarios, el nivel educativo en salud es bajo, lo cual influye en el rechazo de los servicios preventivos y en la posposición de los curativos hasta que aparecen las complicaciones y se presta poca atención a la salud preventiva - agua potable, electricidad, disposición de aguas servidas, basura y desechos contaminantes, desnutrición, prevención de accidentes, etc. (ver E. Selva Sutter, "Al oído de aquellos interesados en la reforma en salud", ECA 619-620, 2000, 573ss.).

Aparte de estas deficiencias generales, tanto el sector público como el privado adolecen de otras propias de cada uno de ellos. En el sector público, las decisiones no son tomadas teniendo en cuenta sólo el bienestar de la población, sino que en ellas influyen también el partidismo político e intereses económicos poderosos en este campo; además de esto, su orientación curativa y hospitalaria menoscaba la preventiva y comunitaria, y su capacidad de servicio se ve muy reducida por un sistema que protege a los trabajadores de la salud de la arbitrariedad del régimen político y por la corrupción. El sector privado que hace de la salud un negocio tampoco es ajeno al partidismo político. Como su criterio más importante es la ganancia, tiende a constituir oligopolios y a practicar la corrupción, a través de comisiones, la referencia de pacientes a determinados especialistas y laboratorios, la utilización de recursos públicos, la doble contabilidad para evadir impuestos, la práctica innecesaria de la terapia y la intervención quirúrgica, la inducción de servicios, etc.

Bastan estas anotaciones para concluir que la situación lamentable en la que se encuentra el sistema de salud salvadoreño está relacionada con la distribución de la pobreza y la riqueza. El sistema mismo es resultado de esa relación dialéctica, en la cual los más pobres, que son la mayoría y los que más necesitan del sistema, son los más desprotegidos, mientras que los más ricos son los que menos lo necesitan, cuando lo necesitan pueden pagarlo y algunos de ellos hacen negocio y se enriquecen aún más a costa de la enfermedad y la necesidad de los demás. El sistema de salud salvadoreño es el sistema de salud de un país pobre, que permite impertérrito que la mayor parte de su 
población subsista en medio de la pobreza, y la pobreza de los servicios que presta es parte integral de esa misma realidad. Pero la pobreza de unos y la riqueza de otros no opera de manera automática. Aun siendo El Salvador un país con un ingreso familiar más bien bajo podría contar con un sistema de salud que satisficiera las necesidades básicas de sus habitantes si los recursos con los que cuenta en la actualidad fuesen administrados de una forma más eficiente. El binomio pobreza - riqueza no es un factor determinante, aunque sí condicionante del sistema de salud actual; es más importante el concepto que se tiene de la salud y de la enfermedad, porque de él depende la distribución y utilización de los recursos disponibles. La tesis que aquí se sostiene es que con los mismos recursos y un concepto adecuado de salud enfermedad es posible contar con un sistema de salud que satisfaga las necesidades básicas de la población salvadoreña.

\section{El concepto humano y social de la salud y la enfermedad}

El concepto adecuado de salud es más importante de lo que parece, porque a primera vista pareciera que entre los especialistas nadie pondría en cuestión la dimensión social de la salud pública. De hecho, en el discurso se encuentran coincidencias en los temas importantes; pero no en la práctica. A hí donde las acciones son determinantes para la vida de las personas se observan dos concepciones muy distintas de lo que debiera entenderse por salud y enfermedad. Estas diferencias obedecen a una formación distinta no exenta de prejuicios, pero también a intereses económicos, los de aquellos para quienes la práctica privada representa un abultado ingreso y los de

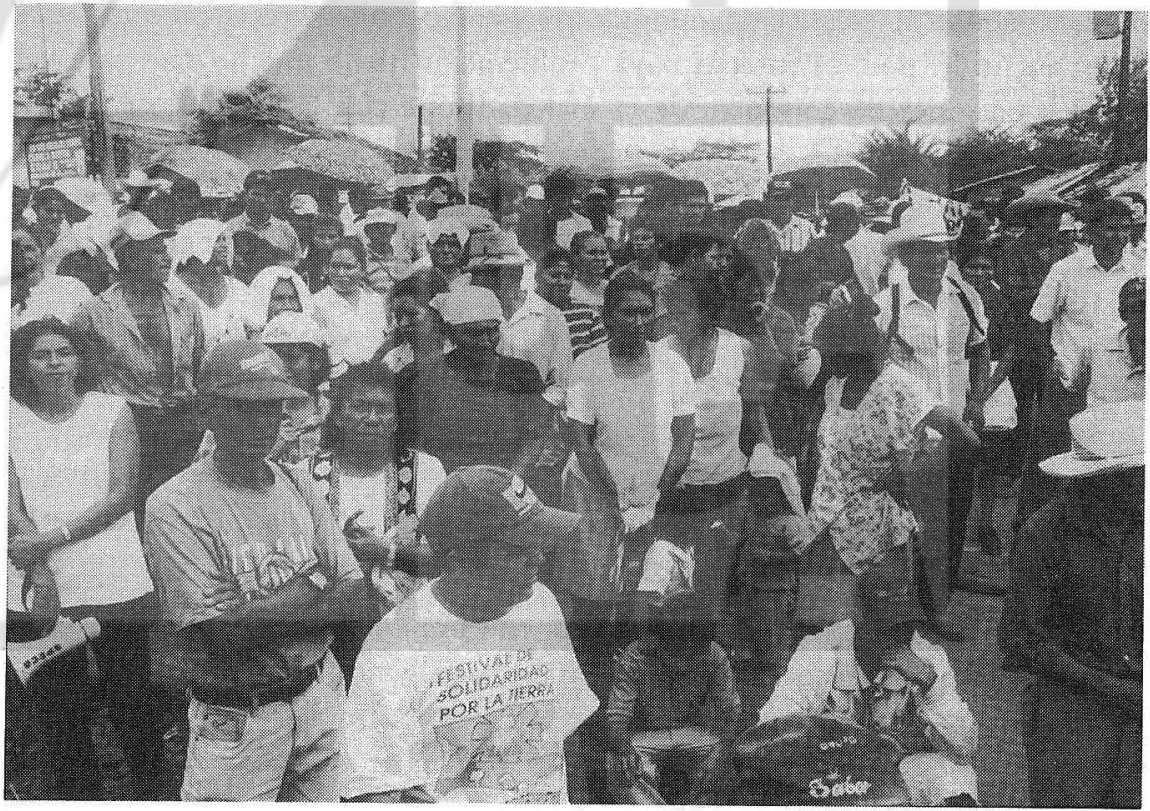


aquellos otros que al concebir la salud sólo como un negocio lucrativo exigen su privatización para aumentar aún más sus ganancias. Los reformadores de la salud pertenecientes a los bancos multilaterales y los gobernantes suelen mirar más a la disminución del gasto público con la privatización de la salud que a las consecuencias sociales y humanas de su decisión.

La práctica predominante en el campo de la salud responde a un concepto que considera a ésta y a la enfermedad como fenómenos separados, de naturaleza esencialmente biológica y, por consiguiente, su enfoque es predominantemente médico. Según esta concepción, la enfermedad sería un hecho individual, originado por la exposición del individuo a un agente biológico o natural —parásitos, bacterias, virus, xenobióticos (arsénico, asbesto, tabaco, alcohol etílico, radiación, presión), etc. En cambio, la salud es definida como la ausencia de enfermedad, es decir, el individuo no mostraría signos ni tendría síntomas $\mathrm{y}$, o los índices de sus funciones fisiológicas - los indicadores biomédicos - se encontrarían dentro de la curva de distribución normal. De esta manera, esta concepción tiende a simplificar los fenómenos complejos, reduciéndolos a causas primarias, a concebir la totalidad como integrada por partes intercambiables, a explicar los hechos en lenguaje biológico, físico y, o químico y a enfatizar la importancia de los hechos establecidos a partir del descubrimiento de relaciones constantes y regulares. Es decir, es un enfoque interesado más en explicar cómo suceden los fenómenos que en comprender qué es lo que en realidad sucede en ellos.

Las limitaciones de esta visión de la salud, que describe la enfermedad a partir de unos cuantos indicadores aceptados tradicionalmente, son puestas en evidencia cuando el sistema de salud colapsa por una crisis como la del dengue hemorrágico, el cual, aunque tiene como causa directa un virus, éste es transmitido por un insecto cuya proliferación tiene mucho más que ver con los patrones de conducta de la sociedad, que con la biología en sí. Así como la dificultad del personal médico para atender los casos individuales está más relacionada con el desconocimiento del manual de medicina general donde se describe la enfermedad, su desarrollo, su diagnóstico y tratamiento, y con la incapacidad del ministerio del ramo para prevenir y enfrentar epidemias, que con el virus mismo. Sólo así se explica que el Ministerio de Salud haya desmantelado la unidad dedicada a vigilar las condiciones propensas para el brote de epidemias o que no cuente con los científicos especializados para controlar los vectores. La estructura de la sociedad, sus patrones sociales y culturales y la degradación del medio ambiente son las que hacen posible las epidemias y buena parte de enfermedades que, de otro modo, serían evitables.

La Organización Mundial de la Salud, en cambio, define la salud como "un estado de completo bienestar físico, mental y social y no solamente como ausencia de afecciones y enfermedades". Para esta concepción, la salud y la enfermedad son elementos de una misma realidad, los cuales no pueden explicarse de 
manera aislada. La enfermedad no se explica si no está referida a la salud y viceversa. La salud es inconcebible sin la superación objetiva de la enfermedad. Este enfoque, que la visión biologista rechaza, explica la salud y la enfermedad por la interacción de la naturaleza y la sociedad. Aunque de la salud y la enfermedad goza y padece el individuo, ambas realidades forman parte de un único proceso. De tal manera que la enfermedad como fenómeno biológico aislable es irreal, aunque cuando se da, requiere de acciones especializadas, pero siempre como parte de un único proceso. Por lo tanto, la salud posee dos formas interrelacionadas e interactuantes, su afirmación actual y su precariedad o negación. Son esas formas las que hacen que la salud posea un carácter intrínsecamente práctico. La salud no se mantiene por inercia o pasividad, sino por acciones concretas sobre la naturaleza y la sociedad, en las cuales los individuos están inmersos y se desenvuelven; estas acciones son todavía más necesarias y deben ser especializadas cuando la estabilidad de la vida es puesta en crisis por la enfermedad. Las posibilidades para superar la crisis son más reales cuanto más efectivas son las acciones.

En el sector público, las decisiones no son tomadas teniendo en cuenta sólo el bienestar de la población, sino que en ellas influyen también el partidismo político e intereses económicos poderosos en este campo [...] El sector privado que hace de la salud un negocio tampoco es ajeno al partidismo político. Como su criterio más importante es la ganancia, tiende a constituir oligopolios y a practicar la corrupción, a través de comisiones, la referencia de pacientes a determinados especialistas y laboratorios...

La salud es una exigencia de la realidad humana, considerada tanto en su dimensión colectiva como individual, que implica un dinamismo constante, el cual tiene mucho de lucha, puesto que no está dada, sino que debe ser conquistada en cada momento. Es este dinamismo el que da pie al enfoque biologista para objetar que la salud es una utopía irrealizable. Sin embargo, la objeción es una excusa para no hacerse cargo de la salud y la enfermedad como un proceso dinámico totalizador y totalizante, que comprende tanto lo colectivo como lo individual, lo natural como lo social. Lo que se niega es que la salud sea compatible con cierta clase de enfermedades, con una vida precaria y con la insatisfacción de necesidades biológicas, psicológicas, culturales y espirituales básicas.

En el otro extremo, la enfermedad incluye no sólo los elementos biomédicos reconocidos internacionalmente, sino también los traumatismos, los traumas, las dolencias, los malestares, las reacciones adversas, las indispo- 
siciones, las emociones nocivas, las angustias, las ansiedades, etc. Estos elementos no sólo entorpecen el desarrollo de una vida normal a quienes los padecen, sino que además surgen y se desarrollan pese a los deseos y, o esfuerzos del individuo para impedir su ciclo natural. Por lo tanto, el desarrollo de la vida individual y colectiva no sólo es obstaculizado o entorpecido por las dolencias oficialmente reconocidas y clasificadas, sino también por todas las otras mencionadas antes y no siempre reconocidas y por todas aquellas otras que impidan el desarrollo normal de los patrones de comportamiento individual y colectivo. La presencia de cualquier proceso cuyo origen patogénico sea reconocible, predecible y relativamente autónomo es una enfermedad y, por eso mismo, produce daño y genera malestar, incapacidad e insatisfacción. Sin embargo, como parte del mismo proceso, la enfermedad es rambién un acicate que estimula y moviliza a la sociedad para superar la crisis creada y conquistar la salud. Lo que sucede es que ésta no puede alcanzarse sin cambios, a veces transcendentales para el desarrollo de la vida individual y, o comunitaria. La vida está garantizada y se vuelve satisfactoria cuando la sociedad y el Estado están comprometidos en una lucha sin cuartel contra la enfermedad y para brindar bienestar y salud a todos sus miembros, sin exclusiones o discriminaciones, aun en el caso de discapacitados o enfermos crónicos.

Desde esta perspectiva, la prevención de la enfermedad adquiere su verdadera dimensión, puesto que se orienta a evitar la creación de condiciones o el aparecimiento de factores que originen dolencias. Ello significa dar a los elementos biológicos que intervienen en el proceso su lugar justo, pero también incluir a todos aquellos que también intervienen en él, aun no siendo de naturaleza biológica. El problema fundamental de la salud en El Salvador - y en otros países - radica en no reconocer que la erradicación de la enfermedad y, por lo tanto, la salud como un estado generalizado de bienestar y satisfacción, sólo son posibles si, además de acciones médicas especializadas e individualizadas, se presta atención rigurosa a la salud pública y a aquellos factores básicos que la ponen en crisis.

Al considerar la salud en estos términos estructurales resulta que las enfermedades principales del pueblo salvadoreño son la desnutrición, los padecimientos con alto componente mental, la violencia, el estrés generalizado, el deterioro del medio ambiente y las dolencias y muertes de los infantes y sus madres. Al analizar cualesquiera de estas dolencias se descubre que ninguna de ellas puede ser superada sin considerar el contexto natural y social. El caso de la desnutrición, que subyace o es resultado de los procesos patológicos, es ilustrativo. La desnutrición es una inmunodeficiencia adquirida muchas veces en el útero materno, pero curable y relacionada con otros elementos que un enfoque biologista ignora. Es paradójico que este enfoque ignore o dé poca importancia a la desnutrición cuando la misma evidencia científica de corte biológico constata que es un fenómeno directamente relacionado con la mitad de todos los casos de mortalidad infantil, en menores de cinco años. Los especialistas conside- 
ran que tres cuartas partes de los niños del mundo que mueren debido a causas relacionadas con la desnutrición, la padecen en grado leve o moderado. En los sobrevivientes, la desnutrición persiste y hace sentir su poder destructivo, ya que padecen discapacidades, muestran mayor propensión a contraer enfermedades y experimentan limitaciones en su actividad intelectual.

La desnutrición está relacionada de manera directa con el nivel del ingreso familiar y la protección social. Los grupos más vulnerables a la desnutrición son los fetos en desarrollo, los niños menores de tres años y las mujeres, antes y durante el embarazo y durante la lactancia. Las enfermedades suelen ser consecuencia de la desnutrición y ésta es, con frecuencia resultado de aquéllas. En realidad, cada tipo de desnutrición es resultado de la interacción de diversos factores, los cuales incluyen variables tan aparentemente ajenas como el acceso de la familia al alimento, al agua potable, a la electricidad, al saneamiento ambiental y a los servicios sanitarios básicos, y la atención materno infantil. De modo más inmediato, la desnutrición está relacionada con las enfermedades y es consecuencia de una alimentación inadecuada. Cuando estas dos variables coinciden, debilitan a quien las padece y, por lo general, la consecuencia es fatal. Además de sufrir un sistema inmunológico débil, los niños desnutridos tienen dificultades para aprender. En edad preescolar, los niños anémicos tienen dificultades para mantener la atención y para distinguir los diversos estímulos. En educación básica y adolescencia, la carencia de hierro hace que el desempeño escolar sea deficiente. Los niños con bajo peso al nacer suelen tener un cociente intelectual menor que los que alcanzan el peso adecuado. La misma deficiencia se observa en aquellos niños que no son amamantados.

Los niños que padecen anemia se convierten en adultos cuyas capacidades físicas e intelectuales están limitadas, a veces seriamente, por lo tanto, su productividad, entendida en sentido amplio, es también limitada y es muy vulnerable a enfermedades crónicas y a padecer discapacidades permanentes. Existe relación entre la desnutrición temprana y el desarrollo posterior de enfermedades coronarias, diabetes y presión arterial alta. El círculo se cierra cuando el adulto vive en una sociedad que no le presta los servicios terapéuticos y de rehabilitación básicos. La desnutrición afecta más a las mujeres que a los hombres, porque se tiende a alimentar mejor a los niños que a las niñas, ya que, según una creencia popular muy extendida, aquéllos son más productivos que éstas. Si la mujer no consigue el desarrollo físico pleno, al embarazo y el alumbramiento presentan complicaciones y, por - _sisiguiente, se encuentra en mayor peligro de muerte que el h....uvre, aparte de dar a luz a un niño desnutrido.

El retraso en el ciecimiento no es la causa directa del desarrollo intelectual deficiente en los niños y las niñas, sino que es muy probable que los mismos factores que retrasan el crecimiento también socaven la posibilidad de un desarrollo 
intelectual normal. Entre estos factores se encuentran peso bajo al nacer, lactancia insuficiente, alimentación baja en calorías, diarrea frecuente e infecciones respiratorias. La nutrición de la madre y del hijo es crucial entre la concepción y los tres primeros años de vida de éste, pero de manera especial en los primeros dieciocho meses, cuando el niño crece de manera muy rápida. En estas circunstancias, la nutrición de las mujeres embarazadas y la lactancia son primordiales. En la mayoría de los casos, el bajo peso al nacer es causado por un desarrollo fetal deficiente y refleja desnutrición en el útero. La interacción entre la ingestión alimentaria inadecuada y las enfermedades crea un círculo vicioso del cual es prácticamente imposible salir si no se adoptan medidas extraordinarias. Cuando la niña desnutrida contrae una enfermedad infecciosa, su resistencia es menor que la de una nutrida, pero, además, su desnutrición aumenta. Estos niños, y en particular las niñas, están menos dotados para rendir en el proceso de enseñanza y aprendizaje, por lo tanto, sus posibilidades para conseguir una buena educación y un empleo bien remunerado son menores. Al no obtener el nivel de ingreso mínimo necesario para adquirir la canasta básica, el círculo de desnutrición, enfermedades infecciosas y pobreza se repite sin solución de continuidad.

\section{El problema fundamental de la salud en El Salvador}

- y en otros países - radica en no reconocer que la erradicación de la enfermedad y, por lo tanto, la salud como un estado generalizado de bienestar y satisfacción, sólo son posibles si, además de acciones médicas especializadas e individualizadas, se presta atención rigurosa a la salud pública y a aquellos factores básicos que la ponen en crisis.

La seguridad alimentaria depende del ingreso y las costumbres del hogar. Sin embargo, el Ministerio de Salud, en su "Reporte epidemiológico semanal", no menciona el estado de la desnutrición de la población salvadoreña -aunque su impacto es evidente en las patologías registradas. En 1998, el 49.75 por ciento de la población salvadoreña vivía en condiciones de pobreza, es decir, 3,007,296 personas — de las cuales casi la mitad $(1,346,407)$ vivía en pobreza extrema - tenían dificultad para alimentarse, protegerse de la agresión de un medio ambiente insalubre y superar las enfermedades. El 23 por ciento de los niños menores de cinco años sufre retardo en el crecimiento (UNICEF, El progreso de las naciones 2000) y el 11 por ciento nace con bajo peso (PNUD, Informe de desarrollo humano 1999). Los casos más extremos de pobreza se encuentran en las áreas rurales de Cabañas, donde casi 9 de cada 10 personas son pobres, y en Morazán, donde 8 de cada 10 son también pobres (ver el "Análisis de coyuntura económica" del Departamento de Economía de la universidad, en esta misma edición). 
cultades que el país enfrenta para abastecer a sus habitantes de agua potable y electricidad y para conservar un medio ambiente sano. Por eso, las reformas hechas hasta ahora, orientadas a prestar una atención médica que busca paliar las infecciones más frecuentes y fortalecer los programas de planificación familiar no son la respuesta adecuada.

\section{Caminos de solución}

Se suele creer que El Salvador carece de los recursos necesarios para resolver sus problemas más graves. Pero esto no pasa de ser una creencia sin fundamento empírico. Al contrario, existen países con un ingreso per cápita similar al de El Salvador, como Sri Lanka, cuya población, sin embargo, goza de unas condiciones de vida mejores, al menos en cuanto a la esperanza de vida, cosa que no es de despreciar. En Sri Lanka, la esperanza de vida al nacer es superior a la de El Salvador en cuatro años; mientras que la tasa de mortalidad de los lactantes es casi el doble en El Salvador que en Sri Lanka. Aunque la tasa de mortalidad de los niños menores de cinco años es similar en los dos países, la tasa de mortalidad materna casi se triplica en El Salvador. La comparación podría alargarse, pero no es necesario. La explicación de esta aparente paradoja reside en que esos países han hecho un esfuerzo considerable en las áreas de salud y educación. Esto muestra sencillamente que una política adecuada podría reducir las tasas actuales de mortalidad a la mitad en El Salvador. La evidencia empírica también demuestra que el crecimiento económico no garantiza el desarrollo humano de manera mecánica, sino que, para avanzar en este campo, es necesario desarrollar políticas sociales eficaces. Es posible, pues, mejorar el estado del desarrollo humano e incluso hacerlo sostenible. Más aún, tal como se afirma en el análisis de la coyuntura económica citado arriba, con una pequeñísima porción del producto interno bruto sería posible hacer desaparecer la pobreza extrema en El Salvador.

Una política de salud adecuada quiere decir aquí, por consiguiente, una política orientada al bienestar de la población y, por ende, con una perspectiva epidemiológica, que privilegie el enfoque social sobre el individual. La salud pública adquiere su dimensión verdadera cuando se rige por los criterios de equidad, calidad de la atención curativa, paliativa y preventiva, calidez en la atención y no discriminación por razones económicas. No se trata de restar importancia al factor económico, sino de evitar la comercialización y el consumismo; de buscar la eficiencia, eliminando la burocratización, la corrupción y el despilfarro. La salud de la población salvadoreña sólo puede progresar si va de la mano de una educación más universal y de mejor calidad, de la ampliación del empleo, del incremento del poder adquisitivo de los salarios y de la conservación del medio ambiente.

A la hora de plantear la salud pública no hay que olvidar que es un derecho fundamental de la humanidad, cuya negación coloca en entredicho al desarrollo 
humano sostenible. En cuanto derecho, no es separable de los otros derechos humanos fundamentales a la alimentación, la educación, la vivienda, la protección, el empleo y el afecto, en una palabra, a la vida justa, libre y digna. La salud es parte esencial de la seguridad humana. De ahí el equívoco de entenderla como ausencia de enfermedad. Ahora bien, cuando la salud se plantea en estos términos y, además, la enfermedad se entiende como un fenómeno biológico, en sentido estricto, el sistema de salud y su posible reforma se proponen en términos exclusivamente médicos o, en el mejor de los casos, orientados a paliar el efecto de la enfermedad en el individuo.

$\checkmark$ Una auténtica reforma del sistema de salud debe buscar proporcionar servicios gratuitos, universales y ordenados de acuerdo al perfil epidemiológico, a la necesidad del usuario y a una visión solidaria, según la cual sus costos sean asumidos de una manera equitativa —a través de impuestos progresivos. La solidaridad y el riesgo compartido son principios básicos en cualquier sistema de salud que pretenda ser público. La experiencia demuestra también que es posible organizar un servicio de salud solidario y equitativo, de tal manera que las necesidades ambulatorias e incluso las especialidades, así como los servicios hospitalarios básicos, cuya sofisticación depende de lo que cada sociedad pueda ofrecerse a sí misma, sean satisfechas. Los servicios de salud de Costa Rica y Cuba tienen estas características. Son servicios universales, de calidad indiscutible y, curiosamente, con un gasto per cápita en el sector similar o ligeramente superior al de El Salvador. Esto significa que en nuestro país, el gasto en salud es ineficiente y la asignación de recursos no es equitativa.

Se suele creer que El Salvador carece de los recursos necesarios para resolver sus problemas más graves. Pero esto no pasa de ser una creencia sin fundamento empírico. Al contrario, existen países con un ingreso per cápita similar al de El Salvador, como Sri Lanka, cuya población, sin embargo, goza de unas condiciones de vida mejores, al menos en cuanto a la esperanza de vida,...

Pero los gobiernos de ARENA no están interesados en esta clase de reformas. Una década no ha sido suficiente para corregir la ineficiencia y suprimir el despilfarro del presupuesto asignado a salud. La explicación es sencilla. Lo que por un lado es mala administración y desperdicio y, por lo tanto, salud precaria si no mala, por el otro, significa enriquecimiento ilícito de unos cuantos. De hecho, una de las causas principales de la ineficiencia salvadoreña se encuentra en la obtención, almacenamiento, distribución, receta y uso de los medicamentos. De todas maneras, es inocultable que el sistema de salud salvadoreño necesita con urgencia una reforma. Cuando el gobierno 
salvadoreño habla de reforma, piensa en privatizar el servicio. Pero la privatización implica, necesariamente, renunciar al principio de cobertura universal, de riesgo compartido y de solidaridad. Los excluidos no sólo serán los más pobres —los que más requieren de estos servicios-, sino también las clases medias, que en la actualidad satisfacen sus necesidades de salud combinando el servicio público con los seguros social y privado. Con toda razón, la mayor parte de la población se opone a la privatización de la salud, puesto que teme que al elevarse sus costos, aquélla quedará más fuera de su alcance. Muchos no aceptan pagar más, aun cuando la calidad sea sustancialmente superior porque, sencillamente, no tienen los medios. Desde un punto de vista racional, es inaceptable lucrarse con la prestación de este servicio cuando existen posibilidades reales de brindar una cobertura universal y de calidad con una mejor organización del sistema. Desde una perspectiva ética, es inmoral hacer dinero a costa de la salud de un pueblo pobre, desnutrido y enfermo, el cual, además, quedará excluido por no poderlo pagar. Desde una perspectiva cristiana, es desentenderse del hermano o de la hermana y abandonarlos a la muerte segura.

Si una cosa han enseñado las privatizaciones hechas hasta ahora por los gobiernos de ARENA, es que los costos de los servicios privatizados son bastante más elevados, tendiendo, por lo tanto, a excluir a quien no puede pagarlos, aun cuando ofrezcan un servicio de calidad superior. Otra de las enseñanzas dejadas por las privatizaciones es la debilidad del Estado salvadoreño para supervisar las operaciones de las nuevas empresas, para garantizar la cobertura y, con ello, la satisfacción de las necesidades de la población. Las instituciones creadas para supervisar las privatizaciones están al servicio de la empresa y del gran capital. No es claro, entonces, por qué la privatización de la salud vaya a ser diferente. Más aún, la experiencia latinoamericana muestra que la salud privatizada tiende a favorecer a quienes gozan de ingresos altos a costa de quienes perciben los más bajos y de una manera muy particular beneficia a las compañías de seguros. La reforma que El Salvador necesita debe ir, justamente, en el sentido contrario, es decir, llevar el servicio a los sectores que perciben los ingresos más bajos, ofreciéndoles acceso a los servicios generales y especializados. Al suprimir la gratuidad del servicio, el sistema privatizado excluye a la mayoría que sobrevive con el salario mínimo y con menos del salario mínimo. La eficiencia de la empresa privada está en entredicho por la falta de competencia y de regulación así como por la corrupción, deficiencias graves a las cuales el Estado no puede poner remedio. A la objeción gubernamental que a cambio de privatizar ofrece como paliarivo los paquetes o las canastas básicas de salud hay que responder que éstos no contribuyen a la equidad, ni garantizan cobertura universal, puesto que los servicios ofrecidos son mínimos o muy reducidos y, además, ineficaces contra las enfermedades no infecciosas que afectan significativamente a la población. La tendencia al oligopolio y la práctica de la corrupción, por otro lado, inevitables en la empresa capitalista de estos tiempos, impiden que el sector privado reemplace el desperdicio y el mal manejo estatal por una administración eficiente. 
En realidad, una corrupción sustituye a otra, a costa de la salud de la población. Sin embargo, manteniendo público el servicio y utilizando bien sus recursos se puede proporcionar cobertura amplia y de calidad e incluso servicios especializados.

Si la privatización no es el camino para garantizar al pueblo salvadoreño su derecho a la salud, la alternativa que queda es la reforma del sistema actual. Pero para que la reforma consiga sus objetivos es necesario, en primer lugar, que tome como punto de partida las necesidades locales y nacionales, lo cual se opone a una reforma impuesta desde el exterior por consultores que, por lo general, desconocen la realidad, la mentalidad y las formas culturales de la sociedad y sus diversos sectores. El actor principal no debiera ser el consultor externo, sino la ciudadanía; el contenido no debiera ser impuesto, sino consensuado, a partir de las iniciativas locales y nacionales. Ahora bien, un proceso así sólo es posible si cuenta con el apoyo del poder político y si se le proporciona un asidero legal. En segundo lugar, uno de los aspectos que debe ser considerado con cuidado a la hora de aceptar las iniciativas para la reforma es su viabilidad técnica y financiera, para lo cual es indispensable el concurso de la ciencia y de la disponibilidad a compartir. En tercer lugar, la reforma debe esforzarse por ofrecer servicios atrayentes para el usuario potencial del sistema, en concreto, por aquel que más necesita de él, porque es el de salud más precaria, quien, además, resulta ser el de menos recursos económicos. Esto va en contra de la actitud muy extendida en la sociedad salvadoreña de imponer métodos draconianos, que en lugar de atraer, alejan. Está tan asimilada la actitud policial y represiva, heredada de los regímenes militares del pasado reciente, que la sociedad misma no encuentra otra alternativa para imponer sus normas de conducta. Aquí de lo que se trata es de que el usuario potencial busque el tratamiento cuando lo necesita y así evitar complicaciones que elevan los costos y aumentan el sufrimiento humano. Dicho de otra manera, el costo de la salud en El Salvador debe bajar de manera drástica, al mismo tiempo que se eleva su eficiencia y calidad. De hecho, es uno de los más caros de América Latina. Si en lugar de bajar, el costo del servicio se eleva, lo más probable es que la población continúe automedicándose o simplemente no acuda a los centros de salud, lo cual, a largo plazo, supone gastos más elevados para la sociedad en su conjunto. En cuarto lugar, el servicio de salud debe descentralizarse, trasladando el primer contacto entre el usuario y el sistema a las comunidades, donde la atención puede ser inmediata, donde el promotor de salud puede contribuir en gran medida a satisfacer la demanda de las comunidades y a prevenir complicaciones posteriores, donde la comunidad tendría espacio para desarrollar un papel activo para conservar su propio estado de salud y el de sus miembros y para exigir un servicio de calidad al centro o unidad de salud, y donde se reducirían los costos de manera considerable por la oportunidad de la intervención y porque descargaría los centros hospitalarios de trabajo. 
Los fracasos de las reformas impulsadas por los organismos internacionales multilaterales y sus consultores extranjeros son una advertencia seria sobre aquello que debiera ser evitado a toda costa, en concreto, la privatización del servicio con menoscabo de la salud de la sociedad; la concentración de la atención en determinados sectores con menoscabo de la promoción de la salud y la prevención de las enfermedades de la generalidad; la atención individualizada con menoscabo de la información y la educación de la comunidad; la centralización del servicio y el énfasis en la curación con menoscabo del desarrollo de la salud comunitaria y medio ambiental; la inversión desproporcionada de recursos en tecnología avanzada con menoscabo de una utilización racional de los mismos; la receta y el uso de medicamentos caros y no esenciales con menoscabo de una medicación más modesta, pero también más efectiva; la concentración en el conocimiento médico con menoscabo de la capacitación en administración y gerencia de la salud pública y comunitaria.

El éxito de la reforma debe ser medido a partir de los objetivos propuestos y no por los avances conseguidos. No es difícil identificar avances, por poco que se haga y aun empleando mal los recursos asignados. Es la táctica de los informes anuales del poder ejecutivo, los cuales sólo presentan los progresos alcanzados durante el año, sin definir nunca objetivos contra los cuales contrastar aquéllos. El mismo criterio se suele utilizar para evaluar las privatizaciones: la privatización, la descentralización, la introducción de nueva tecnología, la disminución del gasto público y el cobro del servicio se consideran logros en sí mismas, haciendo a un lado su cobertura, su eficiencia, su calidad, la satisfacción del usuario y el impacto en las relaciones sociales.

Los obstáculos mayores para impulsar una reforma de la salud pública que satisfaga las necesidades humanas fundamentales provienen de los organismos internacionales multilaterales, los cuales todavía se aferran con obstinación a la privatización, aun sin contar con evidencia empírica que la respalde como la mejor solución para la población más necesitada de servicios públicos; de los prejuicios, compartidos por igual por los políticos, la sociedad e incluso por los mismos médicos, en contra de un servicio más preventivo que curativo, más social que individual, más solidario que discriminatorio; de los diversos intereses económicos que se lucran del servicio de salud pública; de la ausencia de una infraestructura básica que proporcione agua porable, energía eléctrica y un medio ambiente seguro a la población y del predominio de una mentalidad inmediatista, individualista y egoísta, muy poco sensible a las necesidades y al sufrimiento de los demás.

Nada de esto impide, sin embargo, que no se puedan dar los primeros pasos para reformar la salud sobre las líneas de la universalidad, la calidad y la solidaridad y en contra de la atención individual y según la capacidad de pago. Una vez aceptado el horizonte en el cual la reforma debe desarrollarse, se pueden identificar los cambios necesarios, su contenido y sus objetivos específicos, luego ha- 
bría que asegurar la viabilidad técnica, financiera y administrativa de dichos objetivos, al menos en principio, lo cual tendría que impulsar el establecimiento de ciertas condiciones mínimas, sin las cuales no serían posibles. Esta reforma debe ser concebida como un proceso, por lo tanto, sus avances son graduales, pero constantes. La evaluación periódica es el instrumento clave para asegurar el avance hacia el objetivo y para corregir el rumbo si es necesario. Ahora bien, un proceso con estas características exige el esfuerzo interdisciplinario de los especialistas, una voluntad social y política y la eficiencia ejecutiva.

San Salvador, 5 de octubre de 2000. 